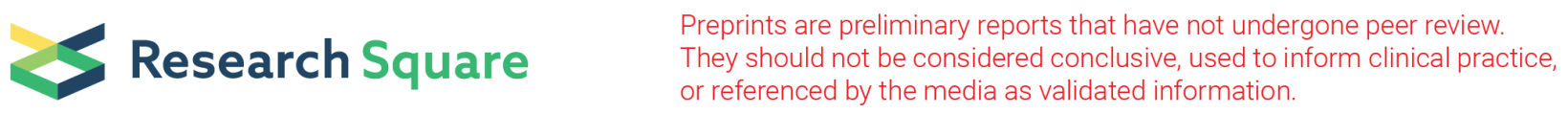

\title{
Effect of Illness Perception on Predicting Breast Cancer-related Lymphedema Risk Management Behaviors Among Breast Cancer Patients: a Comparison Between Dimensions and Profiles
}

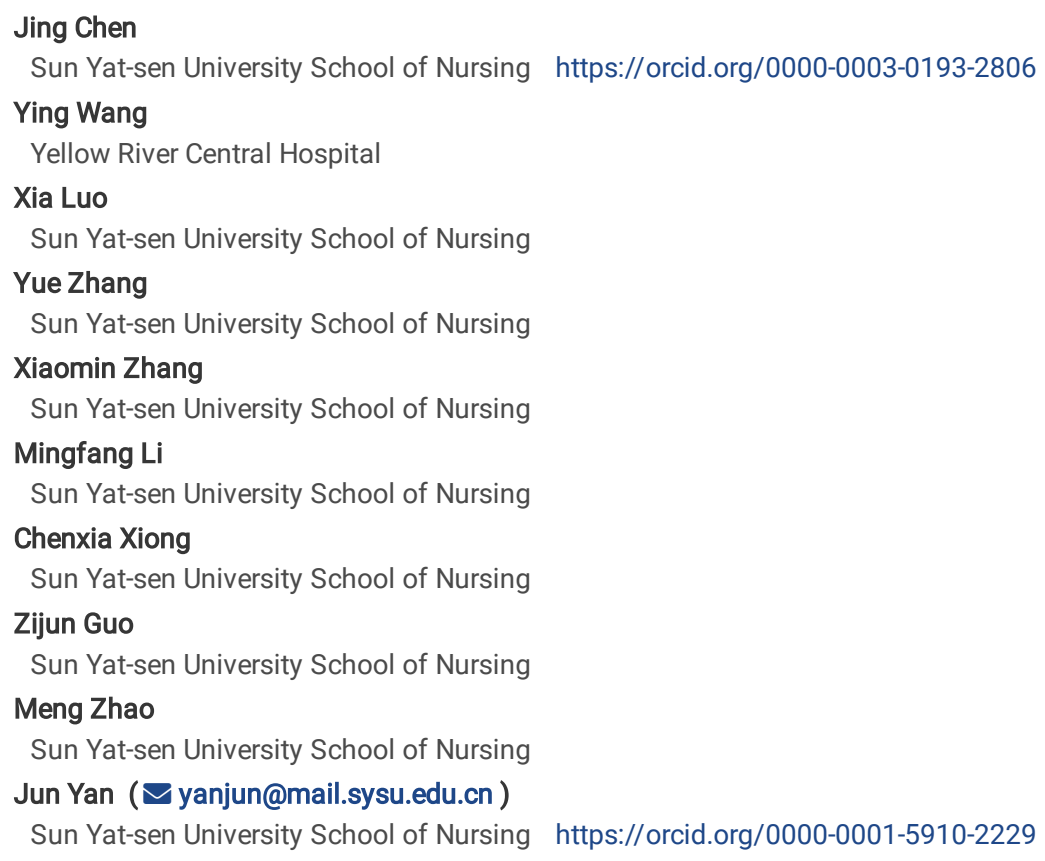

Research Article

Keywords: breast cancer, lymphedema, illness perception, risk management, latent profile analysis

Posted Date: February 15th, 2022

DOI: https://doi.org/10.21203/rs.3.rs-1154486/v1

License: (a) (7) This work is licensed under a Creative Commons Attribution 4.0 International License. Read Full License 


\section{Abstract}

Purpose: To assess illness perceptions regarding breast cancer-related lymphedema (BCRL) before discharge following surgery and BCRL risk management behaviors at 3 months postsurgery among Chinese breast cancer patients and to compare the effects of illness perception dimensions and illness perception profiles on predicting BCRL risk management behaviors using two analysis approaches.

Methods: A total of 213 breast cancer patients completely participated in this follow-up study. The variable-centered approach (i.e., Pearson correlation analysis) and person-centered approach (i.e., latent profile analysis (LPA) followed by comparison between profiles) were adopted to examine the relationship between illness perception and BCRL risk management behaviors. Multiple linear regression analysis was used to compare the amount of variability in BCRL risk management behaviors explained by illness perception dimensions or illness perception profiles.

Results: Using the variable-centered approach, "illness coherence" and "timeline (cyclical)" dimensions were found to be significant components of illness perception predicting BCRL risk management behaviors in the whole population. Using the person-centered approach, LPA identified two profiles and revealed significant differences in BCRL risk management behaviors between them. Overall, illness perception profiles explained smaller amounts of variability in BCRL risk management behaviors than illness perception dimensions at 3 months postsurgery.

Conclusions: Based on illness perception regarding BCRL, breast cancer patients were categorized into two profiles. Illness perception dimensions and illness perception profiles showed certain effects on predicting BCRL risk management behaviors. These two methods provided different perspectives on the design and implementation of future interventions addressing maladaptive illness perception regarding BCRL.

\section{Introduction}

Breast cancer-related lymphedema (BCRL) is an excruciating complication for breast cancer survivors after surgery [1], and more than $20 \%$ of breast cancer patients reportedly suffer from BCRL, with most cases occurring between 3 months and 2 years after surgery [2, 3]. According to recommendations, breast cancer patients should implement some self-management strategies to minimize the risk of BCRL [4-6]. These strategies, also known as BCRL risk management behaviors, include a series of behaviors intended to protect the affected limb from compression, skin wounds and infection. Engaging in these behaviors is critical to minimize the occurrence and progression of BCRL and for cost-effective in the long term [7, 8]. However, patients' BCRL risk management behaviors are influenced by multitudinous factors, with illness perception (IP) emerging as an important indicator.

IP is the main concept of the Common Sense Model (CSM) $[9,10]$ and refers to individuals' views on symptoms, risk factors, time frame (development and duration), consequences, controllability, self-understanding and emotional representations of disease [11, 12]. Numerous studies have demonstrated the significant impact of IP on patients' health behaviors [12-14]. In terms of BCRL, McLaughlin et al [15] pointed out that patients who identified more BCRL symptoms were more focused on protecting their affected limbs. Sherman et al [16] found that patients with a better understanding of BCRL, more confidence in controlling BCRL and fewer negative emotions due to BCRL, were more likely to engage in preventive behaviors. Huang [17] also found that patients who regarded BCRL as a disease with a long duration and serious consequences were more inclined to actively prevent BCRL.

Most previous studies treated dimensions of IP as separate elements and explored their relationships with outcome variables using traditional correlation or regression analysis methods. Notably, these traditional approaches make it difficult to synthesize our understanding of IP and its role in health outcomes [14]. This is theoretically inconsistent with the CSM, where the components of IP are considered different but interrelated parts of a schema rather than isolated elements [9, 14]. Moreover, as variable-centered approaches, traditional approaches provide a single set of parameters for an entire population [18]; that is, these approaches regard all individuals within samples as a whole and ignore the possibility that subgroups presenting differentiated profiles might be hidden among the samples $[19,20]$.

Conversely, person-centered approaches, such as latent profile analysis (LPA), can identify individuals with similar IP and assign them into distinct profiles [21, 22]. Several studies have used this technique to analyze IP data and define meaningful profiles of patients, i.e., Norton [23] identified negative and positive IP groups of rheumatoid arthritis patients. A study categorized 187 older adults with chronic disease into three groups with different IPs [24], and a population of women who tested positive for human papillomavirus was divided into three groups according their distinct IP [25].

Both approaches to analyzing data are viable, and combining the two perspectives is valuable for interpreting the impact of IP on outcome variables and guiding interventions. Two studies have explored this issue. Skinner et al [26] conducted research in type 2 diabetes patients and recommended that a personcentered approach is more useful for understanding patterns of responding to illness than an analysis of IP dimensions independently. Aujla et al [27] performed statistical comparisons of two approaches in poststroke patients but reported that the approach that better predicts outcomes remains unclear. However, no studies to date have explored IP profiles for BCRL in breast cancer patients or compared the two analysis methods.

Therefore, our study aimed to investigate IP regarding BCRL before discharge following surgery and BCRL risk management behaviors at 3 months postsurgery among Chinese breast cancer patients and examine the relationship between IP and BCRL risk management behaviors using correlation analysis methods and LPA followed by comparison between groups. Furthermore, we also compare the amount of variability in BCRL risk management behaviors explained by IP dimensions or IP profiles.

\section{Methods}

\section{Design and participants}


This was a descriptive and exploratory study. A convenience sampling method was adopted. The participants were recruited in the breast surgery ward of a cancer center in Guangzhou, China. Women were eligible for the present study who 1) were aged at least 18 years old; 2) were diagnosed with breast cancer and aware of their cancer diagnosis; 3 ) had undergone breast cancer surgery for the first time, including axillary lymph node dissection or sentinel node biopsy; 4) were able to communicate in Mandarin or Cantonese; and 5) signed informed consent. Women with other cancers, cognitive impairment, metastasis or recurrence of breast cancer were excluded.

\section{Instruments}

\section{Demographic and clinical characteristics}

The demographic data were collected with a form that included age, BMI, education level, marital status, employment status, family residence, etc. The clinical data were obtained from medical records concerning cancer stage, lymph node status, neoadjuvant therapy, family history of breast cancer, and which side was the dominant arm.

\section{Illness perception regarding BCRL}

IP regarding BCRL was measured by a BCRL-specific Chinese version of the Illness Perception Questionnaire-Revised [CIPQ-R(BCRL)] [11]. It consists of 9 dimensions. The cause dimension assessing beliefs in potential risk factors was excluded because the corresponding items were potentially confusing and imposed a heavy response burden (22 items). The identity dimension includes 8 commonly occurring symptoms among BCRL patients. Participants were asked whether they believed that these symptoms were related to BCRL and to provide "yes" or "no" responses. A total of 35 items evaluated the other 7 dimensions using the 5-point Likert scale.

\section{BCRL risk management behaviors}

(1) The Lymphedema Risk Management Behavior Questionnaire (LRMBQ)

In 2018, Huang [17] formed the LRMBQ based on Wang's [28] study, as well as internationally recognized guidelines for BCRL risk management [4, 5]. The LRMBQ contains four dimensions: "avoidance of compression and injury", "skin care", "lifestyle", and "other matters requiring attention". The Likert 5-point scoring method was adopted, where " $1=$ never" and " $5=$ always". Higher scores indicate better adherence to the behaviors. The psychometric test showed acceptable reliability and good content validity [17].

(2) The Functional Exercise Adherence Scale (FEAS)

As an important protective factor for lymphedema, functional exercise was investigated through only one item ("Engaging in appropriate functional exercise of the affected limb every day") on the LRMBQ. Thus, the FEAS, which has good psychometric properties, was added [29]. The FEAS has three dimensions: "adherence to physical exercise", "adherence to actively seeking advice", and "adherence to following the precautions". The scores for each item ranged from 1 (impossible to achieve) to 4 (completely achievable), which higher FEAS scores corresponding to better functional exercise adherence.

\section{Procedure}

The study was approved by the hospital's research ethics committee (L2019ZSLYEC-001). Data collection was conducted from August 2019 to January 2021. Four master's degree students were trained as data collectors. After eligibility was confirmed through the medical records, patients matching the criteria were recruited before discharge following surgery (usually 2 or 3 days after surgery when they received routine postoperative education). Then, they were informed about the purposes, procedures and personal rights of the study and signed an informed consent form. Then, the CIPQ-R (BCRL) and surveys for demographic and clinical characteristics were sent to participants to complete. For patients who were physically unable to complete the questionnaire independently, the data collectors read the items to them and recorded their answers.

Three months after surgery, the questionnaires (LRMBQ and FEAS) were distributed to patients on the day that they returned to the hospital. For patients who had no return plan or could not meet face to face due to the impact of COVID-19, online questionnaires were collected.

\section{Data analysis}

First, using SPSS version 25.0 (Chicago, IL, USA), descriptive statistics were presented as numbers (n), percentages (\%), and the means and standard deviations (SDs). Bivariate correlations between IP dimensions and BCRL risk management behaviors were established by traditional Pearson correlations.

Next, we performed LPA in Mplus version 8.3 to identify the optimal number of profiles and categorize individuals into latent profiles based on their responses on eight IP dimensions. Increasing the unit of profile from 1 to $\mathrm{K}$, a series of latent profile models were fitted to the data until adding more profiles did not improve the explanatory power [20,21]. The best-fitting model was determined based on the following series of model fit statistics [30, 31]. Moreover, interpretability based on theoretical and clinical relevance and parsimony are of equal importance for final model selection, and at least $5 \%$ of the total samples in each profile is acceptable [32,33]. Then, independent sample t tests were performed to examine differences in IP dimensions and BCRL risk management behaviors between latent profiles.

Finally, multiple linear regression models were fitted to assess the amount of variability in BCRL risk management behaviors (at 3 months postsurgery) explained by IP dimensions or IP profiles. A "stepwise" method was manipulated in two steps. First, demographic and clinical variables were entered (Model 1). Second, eight IP dimensions (Model 2) or IP profiles (Model 3) exhibiting significance in Pearson correlation and independent sample t test analyses were entered. Models were compared using changes in $\mathrm{R}^{2}$. 


\section{Results}

In total, we recruited 291 breast cancer patients, among whom 268 agreed to participate and 213 participants completed the follow-up three months after surgery.

\section{Participant characteristics}

The participants' mean age was 48.37 years ( $S D=10.13)$. The average BMI was $23.03 \mathrm{~kg} / \mathrm{m}^{2}(\mathrm{SD}=3.09)$. Among all respondents, $26.8 \%$ had completed college education or above. Most patients were married (accounting for $86.4 \%$ ). Urban residents accounted for $62.0 \%$ of the sample, and $53.1 \%$ of the respondents were unemployed or retired. With respect to clinical characteristics, $83.6 \%$ of the respondents were in cancer stages $\|$ III, and $50.2 \%$ of the patients had positive lymph nodes. Among the respondents, $23.9 \%$ had received neoadjuvant therapy before surgery, a total of 14 respondents had a family history of breast cancer, and 128 patients' affected limbs were their dominant arms. Table 1 presents the respondents' demographic and clinical characteristics. 
Table 1

Demographic and clinical characteristics $(N=213)$

\begin{tabular}{|c|c|c|}
\hline Characteristics & $n$ & $\%$ \\
\hline Age (years) & \multicolumn{2}{|c|}{$48.37 \pm 10.13$} \\
\hline$<40$ & 45 & 21.1 \\
\hline $40 \sim 60$ & 135 & 63.4 \\
\hline$\geq 60$ & 33 & 15.5 \\
\hline $\mathrm{BMI}\left(\mathrm{kg} / \mathrm{m}^{2}\right)$ & \multicolumn{2}{|c|}{$23.03 \pm 3.09$} \\
\hline$<18.5$ & 13 & 6.1 \\
\hline $18.5 \sim 24.0$ & 125 & 58.7 \\
\hline$\geq 24.0$ & 75 & 35.2 \\
\hline \multicolumn{3}{|l|}{ Education level } \\
\hline Primary school or below & 49 & 23.0 \\
\hline Junior high school & 49 & 23.0 \\
\hline Senior high school & 58 & 27.2 \\
\hline College and above & 57 & 26.8 \\
\hline \multicolumn{3}{|l|}{ Marital status } \\
\hline Married & 184 & 86.4 \\
\hline Single/divorced/widowed & 29 & 13.6 \\
\hline \multicolumn{3}{|l|}{ Employment status } \\
\hline Employed & 100 & 46.9 \\
\hline Unemployed/retired & 113 & 53.1 \\
\hline \multicolumn{3}{|l|}{ Residence } \\
\hline Urban & 132 & 62.0 \\
\hline Rural & 81 & 38.0 \\
\hline \multicolumn{3}{|l|}{ Cancer stage } \\
\hline ૧ & 35 & 16.4 \\
\hline ૧ & 114 & 53.5 \\
\hline ૫ & 64 & 30.1 \\
\hline \multicolumn{3}{|l|}{ Lymph node status } \\
\hline Negative & 106 & 49.8 \\
\hline Positive & 107 & 50.2 \\
\hline \multicolumn{3}{|c|}{ Neoadjuvant therapy before surgery } \\
\hline No & 162 & 76.1 \\
\hline Yes & 51 & 23.9 \\
\hline \multicolumn{3}{|c|}{ Family history of breast cancer } \\
\hline No & 199 & 93.4 \\
\hline Yes & 14 & 6.6 \\
\hline \multicolumn{3}{|l|}{ Dominant arm } \\
\hline Unaffected limb & 85 & 39.9 \\
\hline Affected limb & 128 & 60.1 \\
\hline
\end{tabular}


In the total sample, the patients could identify 4.83 BCRL symptoms on average. Referring to the previous literature [34], a one-sample t test was used to compare the mean scores of the other seven dimensions with 3 points (median) to evaluate the tendency of patients' perceptions. The results showed that the mean scores for the "consequences", "personal control", "treatment control" and "emotional representations" dimensions were higher than 3 points, while the mean score of the "illness coherence" dimension was lower than 3 points (see Table 2).

Table 2

Descriptive statistics and correlations of illness perception dimensions with BCRL risk management behaviors

\begin{tabular}{|c|c|c|c|c|c|c|c|c|c|c|}
\hline Variables & Mean $\pm S D$ & $\begin{array}{l}\text { Total } \\
\text { LRMBQ }\end{array}$ & $\begin{array}{l}\text { Avoidance } \\
\text { of } \\
\text { compression } \\
\text { and injury }\end{array}$ & Skin care & $\begin{array}{l}\text { Other } \\
\text { matters } \\
\text { requiring } \\
\text { attention }\end{array}$ & Lifestyle & $\begin{array}{l}\text { Total } \\
\text { FEAS }\end{array}$ & $\begin{array}{l}\text { Adherence } \\
\text { to } \\
\text { physical } \\
\text { exercise }\end{array}$ & $\begin{array}{l}\text { Adherence } \\
\text { to } \\
\text { following } \\
\text { the } \\
\text { precautions }\end{array}$ & $\begin{array}{l}\text { Adherene } \\
\text { to active } \\
\text { seeking } \\
\text { advice }\end{array}$ \\
\hline Mean $\pm S D$ & & $3.92 \pm 0.64$ & $4.61 \pm 0.69$ & $3.75 \pm 0.80$ & $3.97 \pm 0.84$ & $3.50 \pm 0.99$ & $2.89 \pm 0.55$ & $2.68 \pm 0.68$ & $3.57 \pm 0.46$ & $2.50 \pm 0.8$ \\
\hline Identity & $4.83 \pm 2.78$ & 0.119 & 0.119 & 0.102 & 0.113 & 0.052 & 0.032 & 0.021 & 0.064 & 0.012 \\
\hline $\begin{array}{l}\text { Timeline } \\
\text { (acute/chronic) } \\
\text { a }\end{array}$ & $3.12 \pm 0.89$ & 0.095 & -0.037 & 0.079 & 0.059 & $0.137^{\star}$ & 0.105 & 0.115 & 0.028 & 0.086 \\
\hline $\begin{array}{l}\text { Consequences } \\
\mathrm{a}\end{array}$ & $3.43 \pm 0.81^{\star \star \star}$ & -0.071 & -0.076 & -0.021 & -0.093 & -0.044 & -0.028 & -0.021 & -0.007 & -0.043 \\
\hline $\begin{array}{l}\text { Personal } \\
\text { control }^{a}\end{array}$ & $3.65 \pm 0.54^{\star \star \star}$ & 0.054 & 0.008 & -0.005 & 0.107 & 0.054 & 0.069 & 0.059 & 0.022 & 0.085 \\
\hline $\begin{array}{l}\text { Treatment } \\
\text { control }^{a}\end{array}$ & $3.59 \pm 0.58^{\star \star \star}$ & -0.022 & 0.057 & -0.074 & 0.022 & -0.039 & -0.036 & -0.015 & -0.041 & -0.054 \\
\hline $\begin{array}{l}\text { Illness } \\
\text { coherence }^{\text {a }}\end{array}$ & $2.61 \pm 0.86^{\star \star \star}$ & $0.254^{\star \star}$ & 0.052 & $0.188^{* *}$ & $0.234^{\star \star}$ & $0.253^{\star \star}$ & $0.188^{\star \star}$ & $0.142^{*}$ & 0.128 & $0.222^{\star \star}$ \\
\hline $\begin{array}{l}\text { Timeline } \\
\text { (cyclical) }^{a}\end{array}$ & $3.06 \pm 0.70$ & -0.244 ** & -0.092 & $-0.246^{\star *}$ & $-0.147 *$ & $-0.218^{\star *}$ & -0.127 & -0.123 & -0.02 & $-0.147^{\star}$ \\
\hline $\begin{array}{l}\text { Emotional } \\
\text { representations } \\
\text { a }\end{array}$ & $3.15 \pm 0.98^{*}$ & -0.051 & 0.006 & -0.054 & -0.018 & -0.067 & -0.098 & -0.094 & -0.074 & -0.073 \\
\hline
\end{tabular}

The mean total LRMBQ score was $3.92(\mathrm{SD}=0.64)$. Among the four dimensions, the mean score for "avoidance of compression and injury" was the highest $(4.61 \pm 0.69)$. Furthermore, the total FEAS score was $2.89(S D=0.55)$. Among the three dimensions, the mean score for "adherence to following the precautions" ranked first $(3.57 \pm 0.46)$.

The Pearson correlation analysis results in Table 2 showed that the "illness coherence" dimension was positively related to BCRL risk management behaviors (except "avoidance of compression and injury" and "adherence to following the precautions" dimensions); "timeline (cyclical)" dimension presented a negative correlation with several dimensions of BCRL risk management behaviors; "timeline (acute/chronic)" dimension was positively associated with "lifestyle". No significant correlation was found between other study variables.

\section{LPA results}

Table 3 shows the model fit statistics for LPA solutions with one to five profiles. The lowest BIC value and significant P value for the BLRT and LMR-LRT suggested that the two-profile solution was the optimal model. Although the AIC and aBIC were not the lowest for the two-profile solution, the P values for the LMR-LRT in the 3 5-profile solutions were $>0.05$, suggesting little improvement in the explanatory power. 
Table 3

Model fit statistics for the 1 5-profile LPA solutions

\begin{tabular}{|c|c|c|c|c|c|c|c|}
\hline Number of Profile(s) & AIC & $\mathrm{BIC}$ & $\mathrm{aBIC}$ & $\begin{array}{l}\text { BLRT } \\
\text { P value }\end{array}$ & $\begin{array}{l}\text { LMR-LRT } \\
\text { P value }\end{array}$ & Entropy & Proportion of each profile \\
\hline 1 & 4859.724 & 4913.504 & 4862.805 & & & & \\
\hline 2 & 4773.357 & 4857.389 & 4778.172 & $<0.001$ & 0.0296 & 0.699 & $0.268 / 0.732$ \\
\hline 3 & 4751.343 & 4865.627 & 4757.891 & $<0.001$ & 0.2952 & 0.805 & $0.235 / 0.718 / 0.047$ \\
\hline 4 & 4716.815 & 4861.386 & 4725.132 & $<0.001$ & 0.1104 & 0.772 & $0.103 / 0.244 / 0.371 / 0.282$ \\
\hline 5 & 4700.391 & 4875.178 & 4710.405 & $<0.001$ & 0.8071 & 0.818 & $0.042 / 0.150 / 0.615 / 0.057 / 0.136$ \\
\hline \multicolumn{8}{|c|}{$\begin{array}{l}\text { Abbreviation: AIC, Akaike information criterion; BIC, Bayesian information criterion; aBIC, sample size-adjusted BIC; BLRT, the bootstrapped likelihood ratio } \\
\text { test; LMR-LRT, the Lo-Mendell-Rubin likelihood ratio test. }\end{array}$} \\
\hline
\end{tabular}

\section{Profile comparisons}

Comparing the two identified profiles (see Table 4), the profiles presented significant differences in all IP dimensions except for "personal control". Patients in Profile $1(n=57,26.8 \%)$ displayed a moderate symptom identity score, acute and not cyclical timelines, few consequences, high personal and treatment control, fewer emotional responses, and moderate coherence. Participants belonging to Profile 2 ( $n=156,73.2 \%$ ) were characterized by recognition of more BCRL symptoms, chronic and cyclical timelines, more consequences, low coherence and more emotional responses. Notably, both profiles were characterized by high control beliefs, although Profile 1 scored higher for "treatment control" than Profile 2.

Table 4 indicates that patients belonging to the two profiles differed in BCRL risk management behaviors. Profile 1 participants had higher scores for all adherence to BCRL risk management behavior dimensions except for "lifestyle" and "adherence to following the precautions" than Profile 2 participants.

Table 4

Profile comparisons of study variables

\begin{tabular}{|lllll|}
\hline Variables & $\begin{array}{l}\text { Profile } 1 \\
(\mathbf{n}=57)\end{array}$ & $\begin{array}{l}\text { Profile } 2 \\
(\mathbf{n}=156)\end{array}$ & $\boldsymbol{t}$ & \\
\hline Identity & $4.05 \pm 2.89$ & $5.12 \pm 2.70$ & -2.499 & 0.013 \\
\hline Timeline (acute/chronic) & $2.64 \pm 0.87$ & $3.29 \pm 0.83$ & -5.053 & $<0.001$ \\
\hline Consequences & $2.62 \pm 0.61$ & $3.72 \pm 0.66$ & -11.065 & $<0.001$ \\
\hline Personal control & $3.71 \pm 0.49$ & $3.63 \pm 0.56$ & 0.918 & 0.360 \\
\hline Treatment control & $3.77 \pm 0.52$ & $3.53 \pm 0.59$ & 2.765 & 0.006 \\
\hline Illness coherence & $3.06 \pm 0.91$ & $2.45 \pm 0.78$ & 4.877 & $<0.001$ \\
\hline Timeline (cyclical) & $2.42 \pm 0.56$ & $3.29 \pm 0.60$ & -9.485 & $<0.001$ \\
\hline Emotional representations & $2.27 \pm 0.80$ & $3.47 \pm 0.82$ & -9.616 & $<0.001$ \\
\hline Total LRMBQ & $4.13 \pm 0.60$ & $3.84 \pm 0.64$ & 3.003 & 0.003 \\
\hline Avoidance of compression and injury & $4.78 \pm 0.40$ & $4.54 \pm 0.76$ & 2.870 & 0.005 \\
\hline Skin care & $3.97 \pm 0.78$ & $3.67 \pm 0.79$ & 2.457 & 0.015 \\
\hline Other matters requiring attention & $4.22 \pm 0.77$ & $3.88 \pm 0.84$ & 2.668 & 0.006 \\
\hline Lifestyle & $3.71 \pm 0.98$ & $3.42 \pm 0.98$ & 1.932 & 0.055 \\
\hline Total FEAS & $3.04 \pm 0.50$ & $2.83 \pm 0.56$ & 2.453 & 0.015 \\
\hline Adherence to physical exercise & $2.85 \pm 0.63$ & $2.62 \pm 0.69$ & 2.182 & 0.030 \\
\hline Adherence to following the precautions & $3.63 \pm 0.43$ & $3.56 \pm 0.47$ & 1.025 & 0.307 \\
\hline Adherence to actively seeking advice & $2.74 \pm 0.68$ & $2.41 \pm 0.82$ & 2.951 & 0.004 \\
\hline
\end{tabular}

Predictive effects 
Using multiple linear regression models, the mean scores on the total LRMBQ/FEAS and its dimensions were taken as outcome variables, and the demographic and clinical characteristics and IP dimensions/IP profiles were treated as potential predictors. The results are presented in Table 5. The "adherence to following the precautions" dimension was not included in the regression model because no significant relationship existed between this dimension and IP dimensions or profiles (see Tables $2 \& 4$ ).

Table 5

Summary of multiple linear regression models of factors predicting BCRL risk management behaviors

\begin{tabular}{|c|c|c|c|c|c|c|c|c|c|c|c|c|}
\hline \multirow[t]{2}{*}{ Model } & \multicolumn{3}{|l|}{ Total LRMBQ } & \multicolumn{3}{|c|}{$\begin{array}{l}\text { Avoidance of compression } \\
\text { and injury }\end{array}$} & \multicolumn{3}{|l|}{ Skin care } & \multicolumn{3}{|c|}{ Other matters requiring attention } \\
\hline & Predictors & $\mathbf{R}^{2}$ & $\Delta R^{2}$ & Predictors & $\mathrm{R}^{2}$ & $\underset{d}{\Delta R^{2}}$ & Predictors & $\mathbf{R}^{2}$ & $\Delta R^{2}$ & Predictors & $\mathrm{R}^{2}$ & $\underset{d}{\Delta} R^{2}$ \\
\hline $\begin{array}{l}\text { Model } \\
1^{\mathrm{a}}\end{array}$ & $\begin{array}{l}\text { Residence; } \\
\text { Neoadjuvant } \\
\text { therapy before } \\
\text { surgery }\end{array}$ & 0.081 & & -- & -- & & $\begin{array}{l}\text { Residence; } \\
\text { Neoadjuvant } \\
\text { therapy before } \\
\text { surgery }\end{array}$ & 0.051 & & $\begin{array}{l}\text { Education } \\
\text { level; } \\
\text { Neoadjuvant } \\
\text { therapy before } \\
\text { surgery }\end{array}$ & 0.078 & \\
\hline \multirow[t]{2}{*}{$\begin{array}{l}\text { Model } \\
2^{b}\end{array}$} & $\begin{array}{l}\text { Residence; } \\
\text { Neoadjuvant } \\
\text { therapy before } \\
\text { surgery }\end{array}$ & 0.168 & 0.087 & -- & -- & -- & $\begin{array}{l}\text { Residence; } \\
\text { Neoadjuvant } \\
\text { therapy before } \\
\text { surgery }\end{array}$ & 0.112 & 0.061 & $\begin{array}{l}\text { Education } \\
\text { level; } \\
\text { Neoadjuvant } \\
\text { therapy before } \\
\text { surgery }\end{array}$ & 0.116 & 0.038 \\
\hline & $\begin{array}{l}\text { Illness coherence; } \\
\text { Timeline (cyclical) }\end{array}$ & & & -- & & & $\begin{array}{l}\text { Timeline } \\
\text { (cyclical) }\end{array}$ & & & $\begin{array}{l}\text { Illness } \\
\text { coherence }\end{array}$ & & \\
\hline $\begin{array}{l}\text { Model } \\
3^{c}\end{array}$ & $\begin{array}{l}\text { Residence; } \\
\text { Neoadjuvant } \\
\text { therapy before } \\
\text { surgery }\end{array}$ & 0.125 & 0.044 & -- & 0.022 & 0.022 & $\begin{array}{l}\text { Residence; } \\
\text { Neoadjuvant } \\
\text { therapy before } \\
\text { surgery }\end{array}$ & 0.080 & 0.029 & $\begin{array}{l}\text { Education } \\
\text { level; } \\
\text { Neoadjuvant } \\
\text { therapy before } \\
\text { surgery }\end{array}$ & 0.115 & 0.037 \\
\hline & IP profiles & & & IP profiles & & & IP profiles & & & IP profiles & & \\
\hline \multicolumn{13}{|c|}{ a Addition of demographic and clinical variables; } \\
\hline \multicolumn{13}{|c|}{ b Addition of IP dimensions based on Model 1; } \\
\hline \multicolumn{13}{|c|}{ c Addition of IP profiles based on Model 1 ; } \\
\hline
\end{tabular}

Table 5

Summary of multiple linear regression models of factors predicting BCRL risk management behaviors (Continued)

\begin{tabular}{|c|c|c|c|c|c|c|c|c|c|c|c|c|}
\hline \multirow[t]{2}{*}{ Model } & \multirow{2}{*}{$\begin{array}{l}\text { Lifestyle } \\
\text { Predictors }\end{array}$} & \multirow[b]{2}{*}{$\mathrm{R}^{2}$} & \multirow[b]{2}{*}{$\Delta R^{2}$} & \multicolumn{3}{|l|}{ Total FEAS } & \multicolumn{3}{|c|}{ Adherence to physical exercise } & \multicolumn{3}{|c|}{$\begin{array}{l}\text { Adherence to actively } \\
\text { seeking advice }\end{array}$} \\
\hline & & & & Predictors & $\mathbf{R}^{2}$ & $\Delta R^{2}$ & Predictors & $\mathbf{R}^{2}$ & $\Delta R^{2}$ & Predictors & $\mathbf{R}^{2}$ & $\Delta R^{2}$ \\
\hline $\begin{array}{l}\text { Model } \\
1^{\mathrm{a}}\end{array}$ & $\begin{array}{l}\text { Education level; } \\
\text { Neoadjuvant } \\
\text { therapy before } \\
\text { surgery }\end{array}$ & 0.106 & & $\begin{array}{l}\text { BMl; Residence; } \\
\text { Neoadjuvant } \\
\text { therapy before } \\
\text { surgery }\end{array}$ & 0.087 & & $\begin{array}{l}\text { BMl; Residence; } \\
\text { Neoadjuvant } \\
\text { therapy before } \\
\text { surgery }\end{array}$ & 0.082 & & $\begin{array}{l}\text { BMl; } \\
\text { Education } \\
\text { level }\end{array}$ & 0.091 & \\
\hline \multirow[t]{2}{*}{$\begin{array}{l}\text { Model } \\
2^{b}\end{array}$} & $\begin{array}{l}\text { Education level; } \\
\text { Neoadjuvant } \\
\text { therapy before } \\
\text { surgery }\end{array}$ & 0.180 & 0.074 & $\begin{array}{l}\text { BMI; Residence; } \\
\text { Neoadjuvant } \\
\text { therapy before } \\
\text { surgery }\end{array}$ & 0.116 & 0.029 & -- & -- & -- & $\begin{array}{l}\text { BMl; } \\
\text { Education } \\
\text { level }\end{array}$ & 0.131 & 0.040 \\
\hline & $\begin{array}{l}\text { Illness coherence; } \\
\text { Timeline } \\
\text { (cyclical) }\end{array}$ & & & Illness coherence & & & -- & & & $\begin{array}{l}\text { Illness } \\
\text { coherence }\end{array}$ & & \\
\hline $\begin{array}{l}\text { Model } \\
3^{c}\end{array}$ & -- & -- & -- & $\begin{array}{l}\text { BMl; Residence; } \\
\text { Neoadjuvant } \\
\text { therapy before } \\
\text { surgery }\end{array}$ & 0.114 & 0.027 & $\begin{array}{l}\text { BMl; Residence; } \\
\text { Neoadjuvant } \\
\text { therapy before } \\
\text { surgery }\end{array}$ & 0.104 & 0.022 & $\begin{array}{l}\text { BMl; } \\
\text { Education } \\
\text { level }\end{array}$ & 0.123 & 0.032 \\
\hline & -- & & & IP profiles & & & IP profiles & & & IP profiles & & \\
\hline \multicolumn{13}{|c|}{ a Addition of demographic and clinical variables; } \\
\hline \multicolumn{13}{|c|}{ b Addition of IP dimensions based on Model 1; } \\
\hline \multicolumn{13}{|c|}{ c Addition of IP profiles based on Model 1; } \\
\hline d Cha & $2^{2}$ & & & & & & & & & & & \\
\hline
\end{tabular}


For the LRMBQ, in Model 2, the "illness coherence" dimension $(\beta=0.131, t=2.678, P=0.008)$ together with the "timeline (cyclical)" dimension $(\beta=-0.185$, $t=-3.125, P=0.001)$ significantly explained an additional $8.7 \%$ of the overall variance. In Model 3 , "IP profiles" $(\beta=-0.303, t=-3.237, P=0.001)$ additionally explained $4.4 \%$ of the overall variance.

For the FEAS, in Model $2 \&$ Model 3 , the "illness coherence" dimension ( $\beta=0.110, t=2.598, P=0.010)$ and "IP profiles" $(\beta=-0.205, t=-2.512, P=0.013)$ significantly explained an additional $2.9 \%$ and $2.7 \%$ of the overall variance, respectively, in addition to that explained by demographic and clinical variables.

In total, multiple linear regression models showed that IP dimensions significantly explained an additional $2.9 \%$ 8.7\% of the variance in BCRL risk management behaviors, while IP profiles explained an additional $2.2 \% \sim 4.4 \%$ of the variance.

\section{Discussion}

This study is the first to assess IP regarding BCRL before discharge following surgery and BCRL risk management behaviors at 3 months postsurgery among Chinese breast cancer patients and to examine the effect of IP on predicting BCRL risk management behaviors using two analysis approaches (the variablecentered approach and person-centered approach).

In the entire sample, breast cancer patients recognized 4.83 of 8 BCRL symptoms before discharge following surgery. They perceived that BCRL may elicit serious consequences and negative emotions and had positive beliefs regarding the effectiveness of personal efforts and treatment. These findings are generally consistent with those of previous studies $[16,17]$. Nevertheless, the patients had difficulty distinguishing whether BCRL was acute, chronic or cyclical, possibly because BCRL did not occur in our population.

Regarding the patients' BCRL risk management behaviors at 3 months postsurgery, their scores for the LRMBQ and its dimensions were nearly the same as those in Huang's [17] study, indicating certain potential for improvement. In terms of the FEAS scores, our participants performed slightly worse than those in Lan's [35] study but better than the respondents in Lu's [29] research. Differences in the time points of the surveys are one possible reason (2 months postsurgery and less than 1 year after surgery in Lan's and Lu's studies, respectively), and breast cancer patients' adherence to functional exercise has been reported to decline over time [36].

The correlational analyses showed that the "illness coherence" and "timeline (cyclical)" dimensions were significantly associated with BCRL risk management behaviors. Illness coherence reflects whether individuals make sense of their disease and has been demonstrated to be associated with behaviors in a range of conditions, including BCRL $[13,16]$. As shown in Table 2, the mean score for the "illness coherence" dimension was lower than 3 points, representing an orientation toward unclear self-understanding, but it still demonstrated a certain effect in positively predicting BCRL risk management behaviors at 3 months postsurgery. Our result showing a significant predictive relationship between the "timeline (cyclical)" dimension and BCRL risk management behaviors is inconsistent with previous studies' results $[12,13]$, which may be related to the different disease characteristics of the study samples. Future studies are needed to provide further evidence on this point.

In the LPA, two distinct profiles were identified. A systematic review of the literature on person-centered analysis of IP revealed that the profiles ranged from two to three [14]. Comparing the two profiles in Table 4, in line with several previous studies [37, 38], our study did not find a statistically significant difference in "personal control" between the two profiles, which may reflect generally strong personal control beliefs. Although positive beliefs regarding personal control motivate patients to adhere to healthy behaviors, patients with extremely optimistic expectations about their condition may be blind, which may impede illness prevention. Thus, health professionals should focus on patients' suitable confidence regarding illness control.

Interestingly, the patients in Profile 1 (who performed better BCRL risk management behaviors) regarded BCRL as having acute and noncyclical courses and a less negative impact, which is inconsistent with the objective characteristics of BCRL. Hurt et al [39] pointed out that these perceptions may be regarded as "unrealistically positive perceptions". In accordance with the CSM and empirical studies, personality traits, such as optimism, modulate an individual's IP. Patients with high optimism may present a positive perception regardless of whether it is realistic, but they may be depressed at a later stage of the disease [40]. Therefore, the relationship between IP and behaviors should be interpreted with caution.

Consistent with previous studies [14], statistically significant differences were found in BCRL risk management behaviors between the two profiles. Surprisingly, patients showed no significant differences in the "lifestyle" and "adherence to following the precautions" dimensions. One explanation may be the poor discrimination of the items. The score for the "lifestyle" dimension was the lowest among the LRMBQ dimensions. Some behaviors in this dimension are rarely carried out by Chinese women, such as "wearing gloves when doing housework" [17, 28]. The score for "adherence to following the precautions" ranked first in the FEAS dimensions, where some behaviors (e.g., not wearing clothes with tight sleeves) could be managed without difficulty.

As shown in Table 5, the results indicated that IP profiles explained smaller amounts of variability than IP dimensions in BCRL risk management behaviors at 3 months postsurgery. This finding is consistent with that of Aujla et al [27]. The weaker effect of IP profiles may be a reflection of the inherent weakness of LPA. Similar to converting multiple continuous data to dichotomizing data, LPA weakens the amount of variability explained by IP.

\section{Clinical implications}

Both statistical methods have the potential to detect novel relationships and provide insights for clinical practice. First, the variable-centered analysis revealed which IP component can significantly predict BCRL risk management behaviors in the whole population. Based on these results, a postsurgical breast cancer patient with a low "illness coherence" or high "timeline (cyclical)" score deserves special attention, and corresponding education or intervention should be provided to prevent their poor BCRL risk management behaviors 3 months postsurgery. Meanwhile, the fact that the health care workforce is insufficient and lacks a balanced distribution should be considered. Formulating individualized plans for every patient may not be achievable in clinical settings. The person-

Page 9/12 
centered analysis identified two profiles, and differences were found in BCRL risk management behaviors between them. With online assessments in the future, these results may help us quickly locate patients in corresponding profiles. Formulating intervention strategies targeted to IP profiles and implementing adjustments following the characteristics of specific patients could be convenient for health care providers, so as to save medical resources and optimize the allocation of medical resources.

\section{Limitations}

Importantly, our study had several limitations. First, the participants were recruited nonrandomly from a single hospital in Guangzhou, which ensured certain homogeneity among the samples but limits the generalizability of the findings in other regions. Second, the amounts of variability in BCRL risk management behaviors explained by IP (dimensions and profiles) were small, suggesting that significant factors influencing BCRL risk management behaviors still need to be explored. Notably, the recently developed LRMBQ used in this study has not been verified because it has not been widely applied. Third, the classification quality of our study was not ideal (entropy=0.699), possibly because our sample size just reached the minimum size for person-centered analysis ( $\mathrm{n}=200$ ) [18].

\section{Conclusion}

Based on IP regarding BCRL, breast cancer patients were categorized into two profiles. The effects of IP dimensions or IP profiles on predicting BCRL risk management behaviors were demonstrated to differ. These two methods offered different perspectives on the design and implementation of future interventions addressing maladaptive IP regarding BCRL.

\section{Declarations}

\section{Acknowledgments}

We would also like to acknowledge all researchers and participants in this study.

\section{Funding}

This work was supported by National Natural Science Foundation of China (Grant number: 71974217).

\section{Author Contributions}

All authors contributed to the study conception and design. Material preparation and data collection was performed by Jing Chen, Xia Luo, Yue Zhang and Xiaomin Zhang. All authors contributed in the analysis and interpretation of the data. The first draft of the manuscript was written by Jing Chen, Ying Wang, Mingfang Li, Chenxia Xiong, and Jun Yan. The manuscript was revised and visualized by Jing Chen, Zijun Guo, Meng Zhao and Jun Yan. Ying Wang and Jun Yan were in charge of supervision and project administration. All authors read and approved the final manuscript.

\section{Data availability}

The data supporting the findings of this study are available from the corresponding author upon reasonable request.

\section{Code availability}

Not applicable.

\section{Ethics approval}

The study was approved by the hospital's research ethics committee (L2019ZSLYEC-001), and we conducted the survey in line with the relevant ethical guidelines such as the Declaration of Helsinki.

\section{Consent to participate}

Informed consent was obtained from all individual participants included in the study.

\section{Consent to publication}

Not applicable.

\section{Competing Interests}

The authors have no competing interests to disclose.

\section{References}

1. Pappalardo M, Starnoni M, Franceschini G, Baccarani A, De Santis G (2021) Breast cancer-related lymphedema: Recent updates on diagnosis, severity and available treatments. J Pers Med 11:402. https://doi.org/10.3390/jpm11050402

2. Ribeiro Pereira ACP, Koifman RJ, Bergmann A (2017) Incidence and risk factors of lymphedema after breast cancer treatment: 10 years of follow-up. Breast 36:67-73. https://doi.org/10.1016/j.breast.2017.09.006

Page $10 / 12$ 
3. DiSipio T, Rye S, Newman B, Hayes S (2013) Incidence of unilateral arm lymphoedema after breast cancer: a systematic review and meta-analysis. Lancet Oncol 14:500-515. https://doi.org/10.1016/S1470-2045(13)70076-7

4. American Cancer Society (2021) For People at Risk of Lymphedema. https://www.cancer.org/treatment/treatments-and-side-effects/physical-sideeffects/lymphedema/for-people-at-risk-of-lymphedema.html. Accessed 21 October 2021

5. National Cancer Institute (2021) Lymphedema (PDQ®)-Patient Version. https://www.cancer.gov/about-cancer/treatment/sideeffects/lymphedema/lymphedema-pdq. Accessed 21 October 2021

6. Armer JM, Ostby PL, Ginex PK et al (2020) ONS Guidelines (TM) for cancer treatment-related lymphedema. Oncol Nurs Forum 47:518-538. https://doi.org/10.1188/20.0NF.518-538

7. Ostby PL, Armer JM, Smith K, Stewart BR (2018) Patient perceptions of barriers to self-management of breast cancer-related lymphedema. West J Nurs Res 40:1800-1817. https://doi.org/10.1177/0193945917744351

8. Radina ME, Armer JM, Stewart BR (2014) Making self-care a priority for women at risk of breast cancer-related lymphedema. J Fam Nurs 20:226-249. https://doi.org/10.1177/1074840714520716

9. Leventhal H, Phillips LA, Burns E (2016) The Common-Sense Model of Self-Regulation (CSM): a dynamic framework for understanding illness selfmanagement. J Behav Med 39:935-946. https://doi.org/10.1007/s10865-016-9782-2

10. Hagger MS, Orbell S (2003) A meta-analytic review of the common-sense model of illness representations. Psychol Health 18:141-184. https://doi.org/10.1080/088704403100081321

11. Huang WB, Zhang LJ, Yan J (2019) Psychometric evaluation of the Chinese version of the revised illness perception questionnaire for breast cancerrelated lymphedema. Eur J Cancer Care 28:e12900. https://doi.org/10.1111/ecc.12900

12. Richardson EM, Schuez N, Sanderson K, Scott JL, Schuez B (2017) Illness representations, coping, and illness outcomes in people with cancer: a systematic review and meta-analysis. Psychooncology 26:724-737. https://doi.org/10.1002/pon.4213

13. Aujla N, Walker M, Sprigg N, Abrams K, Massey A, Vedhara K (2016) Can illness beliefs, from the common-sense model, prospectively predict adherence to self-management behaviours? A systematic review and meta-analysis. Psychol Health 31:931-958. https://doi.org/10.1080/08870446.2016.1153640

14. Rivera E, Corte C, DeVon HA, Collins EG, Steffen A (2020) A systematic review of illness representation clusters in chronic conditions. Res Nurs Health 43:241-254. https://doi.org/10.1002/nur.22013

15. McLaughlin SA, Wright MJ, Morris KT et al (2008) Prevalence of lymphedema in women with breast cancer 5 years after sentinel lymph node biopsy or axillary dissection: Patient perceptions and precautionary behaviors. J Clin Oncol 26:5220-5226. https://doi.org/10.1200/JC0.2008.16.3766

16. Sherman KA, Miller SM, Roussi P, Taylor A (2015) Factors predicting adherence to risk management behaviors of women at increased risk for developing lymphedema. Support Care Cancer 23:61-69. https://doi.org/10.1007/s00520-014-2321-1

17. Huang WB (2018) Illness perception and lymphedema risk management behavior among breast cancer survivors. Dissertation, Sun Yat-sen University

18. Howard MC, Hoffman ME (2018) Variable-centered, person-centered, and person-specific approaches: Where theory meets the method. Organ Res Methods 21:846-876. https://doi.org/10.1177/1094428117744021

19. Meyer JP, Morin AJS (2016) A person-centered approach to commitment research: Theory, research, and methodology. J Organ Behav 37:584-612. https://doi.org/10.1002/job.2085

20. Ferguson SL, Moore EWG, Hull DM (2020) Finding latent groups in observed data: A primer on latent profile analysis in Mplus for applied researchers. Int J Behav Dev 44:458-468. https://doi.org/10.1177/0165025419881721

21. Wang MC, Bi XY (2018) Latent variable modeling using Mplus. Chongqing University Press, Chongqing.

22. Dunn H, Quinn L, Corbridge SJ, Eldeirawi K, Kapella M, Collins EG (2018) Cluster analysis in nursing research: An introduction, historical perspective, and future directions. West J Nurs Res 40:1658-1676. https://doi.org/10.1177/0193945917707705

23. Norton S (2014) Negative and positive illness representations of rheumatoid arthritis: A latent profile analysis. J Behav Med 37:524-532. https://doi.org/10.1007/s10865-013-9506-9

24. Rivera E, Corte C, Steffen A, DeVon HA, Collins EG, McCabe PJ (2018) Illness representation and self-care ability in older adults with chronic disease. Geriatrics 3:45. https://doi.org/10.3390/geriatrics3030045

25. McBride E, Marlow LAV, Chilcot J, Moss-Morris R, Waller J (2021) Distinct illness representation profiles are associated with anxiety in women testing positive for human papillomavirus. Ann Behav Med. https://doi.org/10.1093/abm/kaab022

26. Skinner TC, Carey ME, Cradock S et al (2011) Comparison of illness representations dimensions and illness representation clusters in predicting outcomes in the first year following diagnosis of type 2 diabetes: Results from the DESMOND trial. Psychol Health 26:321-335.

https://doi.org/10.1080/08870440903411039

27. Aujla N, Walker M, Sprigg N, Vedhara K (2020) Do individual versus illness belief schema differ in the prediction of post-stroke recovery? J Health Psychol 25:2118-2128. https://doi.org/10.1177/1359105318785446

28. Wang L (2013) The establishment and evaluation of scoring system for predicting the risk of breast cancer-related Lymphedema. Dissertation, AnHui Medical University

29. Lu FJ (2008) Compliance and related factors to functional exercise protocol among postoperative breast cancer patients after discharge. Dissertation, Sun Yat-sen University

30. Tein JY, Coxe S, Cham H (2013) Statistical power to detect the correct number of classes in latent profile analysis. Struct Equ Modeling 20:640-657. https://doi.org/10.1080/10705511.2013.824781 
31. Duprez V, van der Kaap-Deeder J, Beeckman D, Verhaeghe S, Vansteenkiste M, Van Hecke A (2020) Nurses' interaction styles when supporting patients in self-management: A profile approach. Int J Nurs Stud 110:103604. https://doi.org/10.1016/j.jjnurstu.2020.103604

32. Spurk D, Hirschi A, Wang M, Valero D, Kauffeld S (2020) Latent profile analysis: A review and "how to" guide of its application within vocational behavior research. J Vocat Behav 120:103445. https://doi.org/10.1016/j.jvb.2020.103445

33. Drake DA, Steege LMB (2016) Interpretation of hospital nurse fatigue using latent profile analysis. Adv Nurs Sci 39:E1-E16. https://doi.org/10.1097/ANS.0000000000000130

34. Cherrington CC, Lawson TN, Clark KB (2006) IIIness representation of patients with systolic heart failure. Prog Cardiovasc Nurs 21:190-195. https://doi.org/10.1111/j.0889-7204.2006.05600.x

35. Lan ML, Zhang LJ, Zhang YN, Yan J (2019) The relationship among illness perception, coping and functional exercise adherence in Chinese breast cancer survivors. J Adv Nurs 75:75-84. https://doi.org/10.1111/jan.13832

36. Petito EL, Nazario ACP, Martinelli SE, Facina G, De Gutierrez MGR (2012) Application of a domicile-based exercise program for shoulder rehabilitation after breast cancer surgery. Rev Lat Am Enfermagem 20:35-43. https://doi.org/10.1590/S0104-11692012000100006

37. Berry E, Davies M, Dempster M (2017) Illness perception clusters and relationship quality are associated with diabetes distress in adults with Type 2 diabetes. Psychol Health Med 22:1118-1126. https://doi.org/10.1080/13548506.2017.1281976

38. Lopes AC, Xavier RF, Pereira ACAC et al (2019) Identifying COPD patients at risk for worse symptoms, HRQoL, and self-efficacy: A cluster analysis. Chronic Illn 15:138-148. https://doi.org/10.1177/1742395317753883

39. Hurt CS, Burn DJ, Hindle J, Samuel M, Wilson K, Brown RG (2014) Thinking positively about chronic illness: An exploration of optimism, illness perceptions and well-being in patients with Parkinson's disease. Br J Health Psychol 19:363-79. https://doi.org/10.1111/bjhp.12043

40. Vollmann M, Scharloo M, Langguth B, Kalkouskaya N, Salewski C (2014) Illness representations as mediators of the relationship between dispositional optimism and depression in patients with chronic tinnitus: A cross-sectional study. Psychology \& Health 29:81-93.

https://doi.org/10.1080/08870446.2013.828294 